\title{
Всероссийская стратегическая сессия по направлениям развития фотоники как "сквозной" технологии НТИ
}

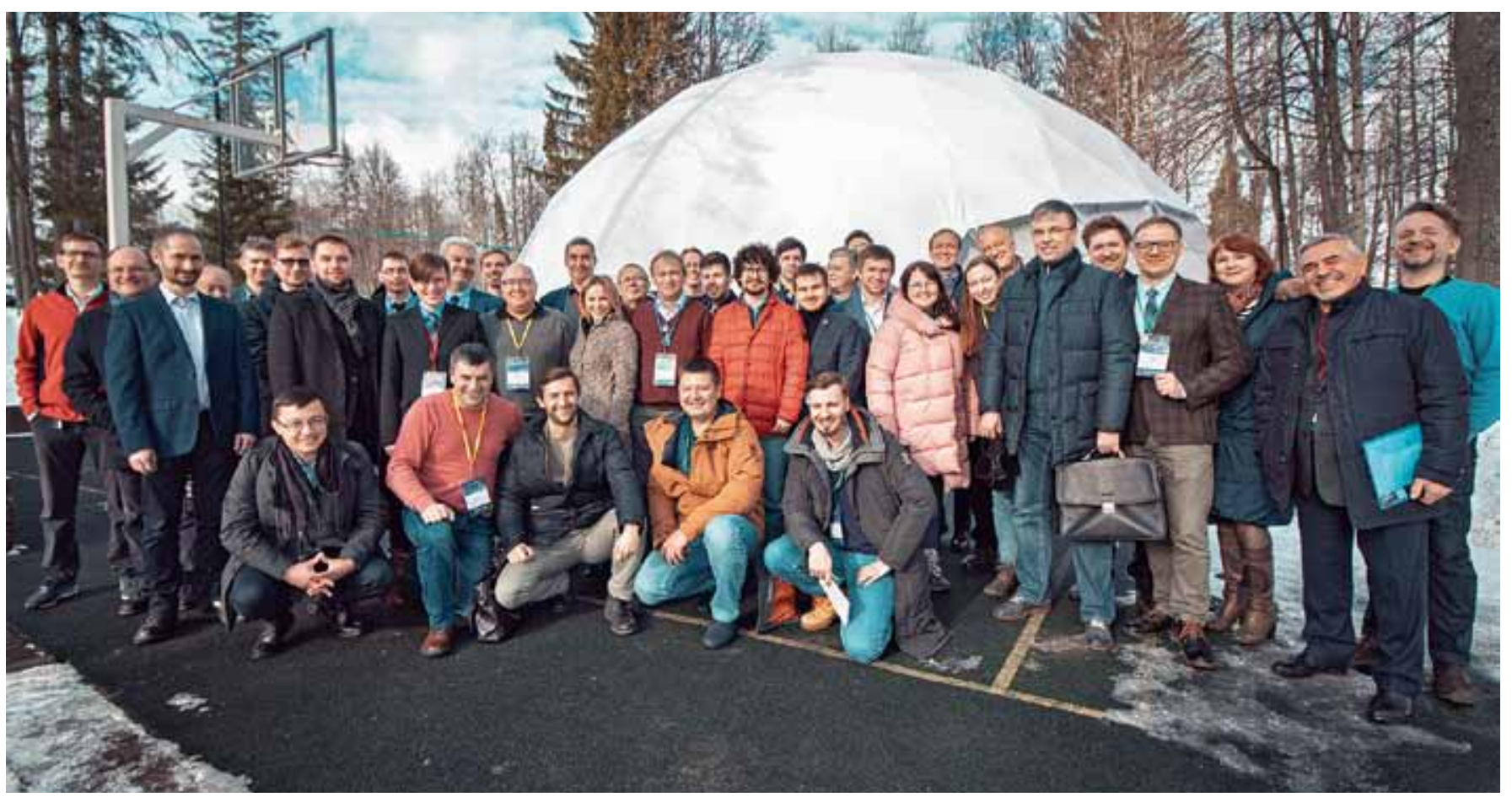

Пермь стала 20-22 марта 2020 года местом проведения Всероссийской стратегической сессии по направлениям развития фотоники как "сквозной" технологии НТИ. Организатором мероприятия стали правительство Пермского края, АНО «Платформа НТИ", АО «Российская венчурная компания" (Проектный офис НТИ) и кластер "Фотоника" во главе с Пермской научнопроизводственной приборостроительной компанией.

Кластер "Фотоника" имеет два федеральных статуса: приоритетный инновационный территориальный кластер России и промышленный кластер (http://pnppk.ru/ru/home/fotonika). Он включает в себя Пермскую научно производственную приборостроительную компанию (ПнППК), Пермский национальный исследовательский политехнический университет (ПНИПУ), Пермский государственный национальный исследовательский университет (ПГНИУ). Подписание соглашения с администрациями Пермского края, Свердловской области и Удмуртской Республики по объединению предприятий этих регионов в раз- работке и создании новых изделий расширило возможности промышленного кластера "Фотоника".

Именно в области фотонных и оптических технологий наблюдается стремительный рост числа новых продуктов, врывающихся на промышленные рынки и меняющих их привычную структуру. Исследования и разработки в области фотоники объединяют в себе фундаментальные и прикладные исследования в разных направлениях физики, механики, математики, информатики, океанологии, медицинской физики и геофизики. В России плодотворно работают старые научные школы, возникают и раз- 
виваются новые перспективные направления исследований. Однако усилившийся в силу кризисных явлений разрыв между уровнем разработок фотонных продуктов и уровнем их промышленного воплощения стал заметной угрозой развитию страны. Резкое изменение характера межгосударственных хозяйственных связей, колебания общественно-политических отношений требуют создания промышленных производств на новой технологической базе и укрепления позиций на глобальном рынке.

Каждое государство, независимо от принятой им модели экономического развития, проводит промышленную политику: оно либо выстраивает четкую систему приоритетов, либо играет ту роль, которую ей позволяют вести развитые технологические державы. Главная цель промышленной политики - это создание промышленности, конкурентоспособной в международном масштабе, обеспечивающей стабильный уровень жизни населения. Методы и инструменты промышленной политики разных стран отличаются между собой: многие находят свои методы по аналогии с опытом других государств, иные принимают решения на основании собственного опыта. Иногда практика государственной поддержки слабеющих отраслей или инновационных проектов превращается в бесперспективное отвлечение средств федерального бюджета, иногда превращается в благоприятные условия для рождения новых компаний, создающих новые рынки.
Стратегия научно-технического развития Российской Федерации (Указ Президента РФ от 1 декабря 2016 г. № 642) направлена на модернизацию экономики в условиях ограниченных бюджетных средств, когда требуются эффективные механизмы привлечения инвесторов

\section{Именно в области фотонных и оптических технологий наблюдается стремительный рост числа новых продуктов, врывающихся на рынки и меняющих их привычную структуру}

в создание высокотехнологических производств. Программно-целевой метод является проверенным инструментом промышленной политики. Трудности его использования превращаются в конкретные барьеры для исполнения программ: инвестиционные риски на мезоуровне находятся в тесной взаимосвязи с рисками на микро- и макроуровне, на этапе создания дорожных карт развития известна только тематика работ, но не известны их результаты, номенклатура продукции курируется профильными федеральными органами исполнительной власти. Поэтому самый ответственный механизм в функционировании комплекса программ - это координация мероприятий, проводимых в его рамках.

Программа НАЦИОНАЛЬНАЯ ТЕХНОЛОГИЧЕСКАЯ ИНИЦИАТИВА (НТИ) долгосрочная комплексная программа по созданию условий для обеспече-
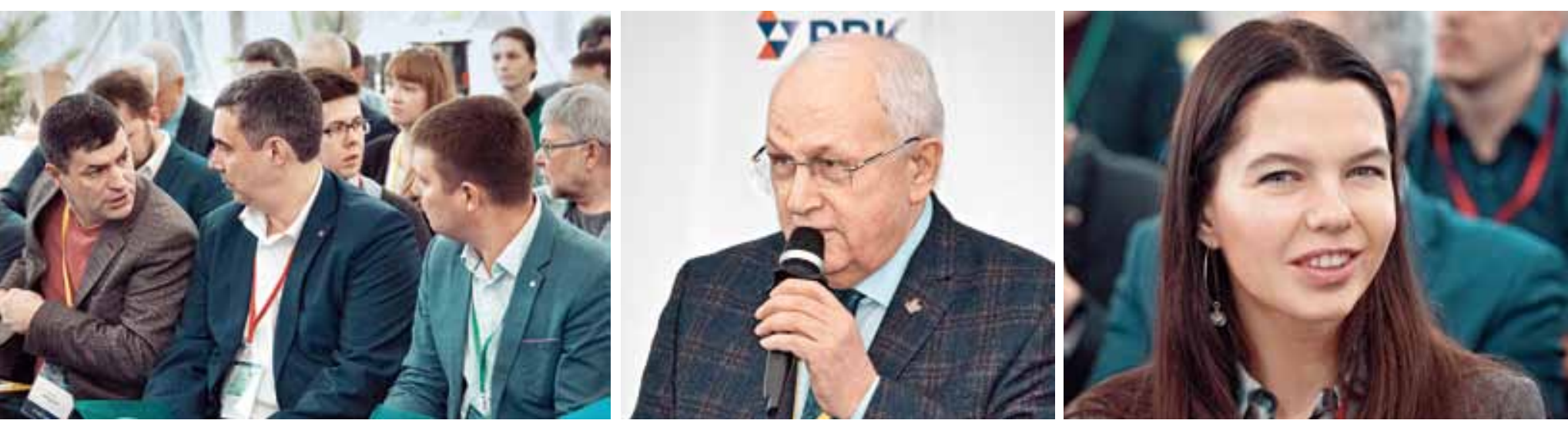

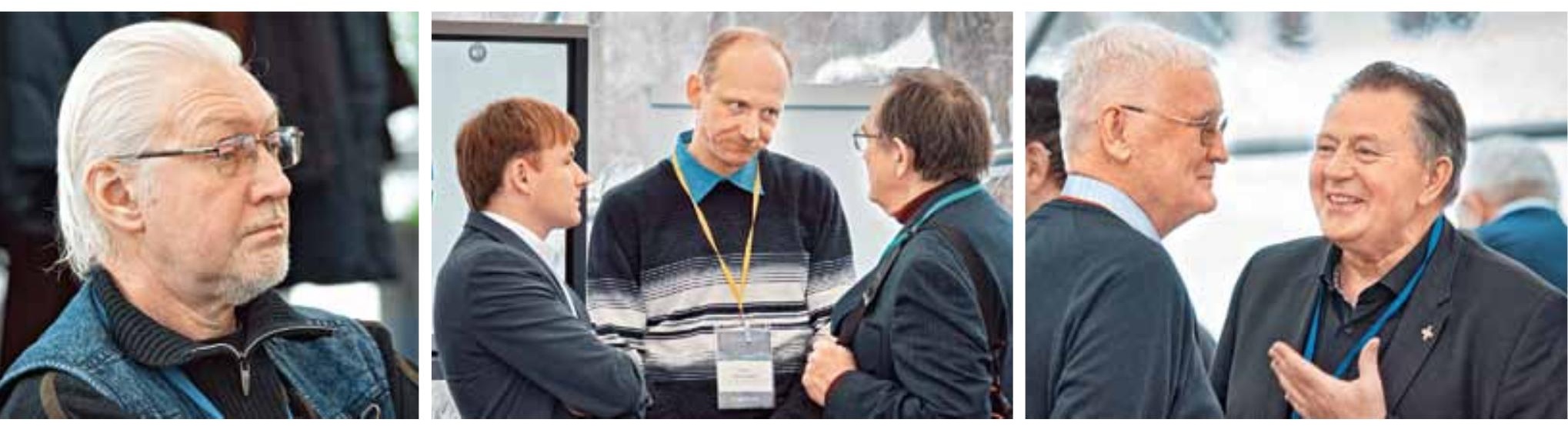

ния лидерства российских компаний на новых высокотехнологичных рынках, которые будут определять структуру мировой экономики в ближайшие 15-20 лет. Ее логика отличается от логики других программ технологического развития. Главное, что программа НТИ объединяет людей, а не организации. Программа НТИ изначально предполагает вовлечение проектных групп из технологических предпринимателей, представителей ведущих университетов и исследовательских центров, крупных деловых

\section{Программа НТИ объединяет Аюдей, а не организащии}

объединений России, институтов развития, экспертных и профессиональных сообществ и заинтересованных органов исполнительной власти. НТИ - национальная программа, но она не отрицает международное сотрудничество, считая, что залог успеха отечественных высоко- технологичных компаний в мире глобальных технологий - это кооперация с международными партнерами. Задача состоит в развитии предпринимательской инициативы в целях обеспечения трансфера технологий из университетских и научных центров. Чтобы получить ответы на многие вопросы, в том числе, зачем нужно развивать новые технологические бизнесы, если под них еще нет рынка, стоит зайти на сайт НТИ: www. nti2035.ru.

Среди направлений реализации своей деятельности НТИ выделяет "сквозные" технологии. Это те технологии, которые способны радикально изменить ситуацию на существующих рынках и даже способны сформировать новые рынки. Фотоника включена в перечень "сквозных" технологий НТИ (наряду с такими технологиями, как технологии хранения и анализа больших данных, технологии искусственного интеллекта, робототехники и мехатроники) в конце 2019 года. Это позволит ускорить привлечение
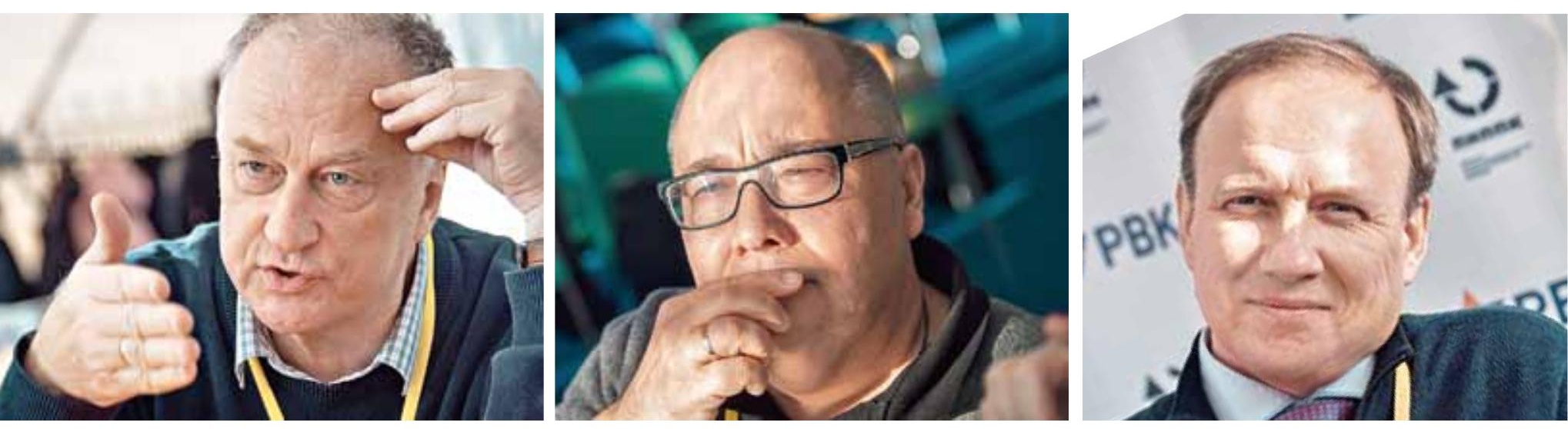

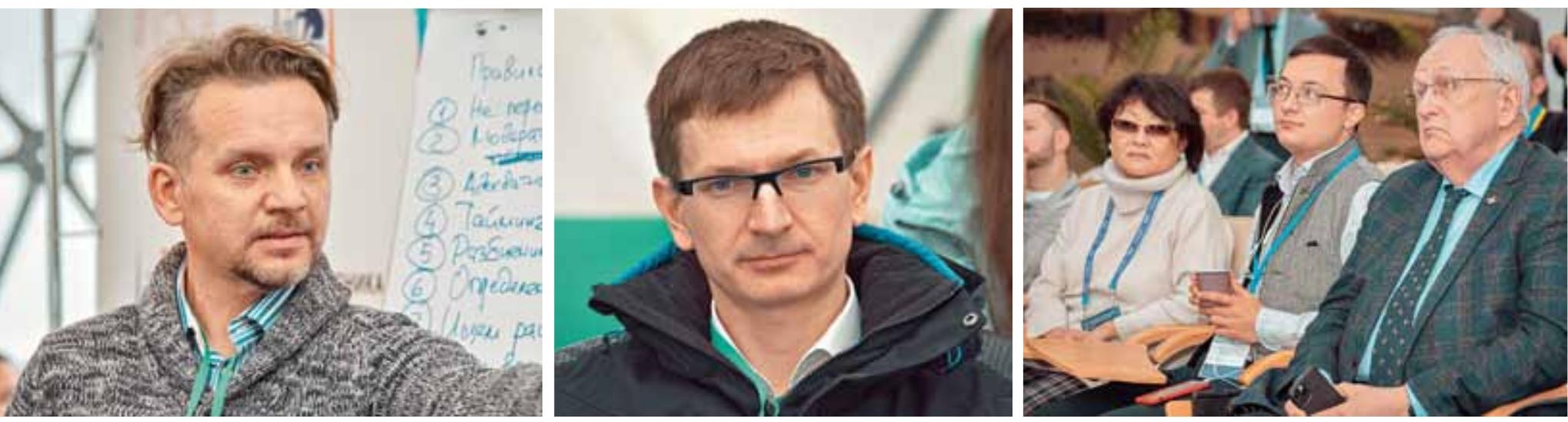

новых инициативных людей и рост числа проектов. Что станет достойным вкладом в реализацию Стратегии научнотехнологического развития РФ.

Центрам компетенций НТИ, которые объединят высшие образовательные и научные организации с хозяйствующими субъектами, включая промышленные предприятия, и которые могут работать в логике НТИ, будет оказана государственная поддержка. На получение статуса такого Центра компетенций НТИ могут претендовать организации пермского кластера "Фотоника".

Функциями проектного офиса Национальной технологической инициативы в части организации конкурсного отбора, организации экспертизы заявок, сопровождения и мониторинга деятельности центров наделено АО "Российская венчурная компания". Другими институтами развития, которые участвуют в реализации НТИ, являются "Агентство стратегических инициатив" (АСИ), Сколково, ФСИ, ВЭБ и многие иные. АСИ -
"Агентство стратегических инициатив по продвижению новых проектов" - является автономной некоммерческой организацией, учрежденной правительством РФ в целях содействия развитию соци-

\section{Первым барьером, который пришлось преодолеть участникам сессии, стала проблема толкования базовых терминов}

альной и профессиональной мобильности молодых профессиональных кадров и коллективов в сфере среднего предпринимательства и социальной сфере путем поддержки общественно значимых проектов и инициатив (https://asi.ru).

Теперь, когда четко сформулированы цели, определены задачи, распределены роли и выбраны игроки, можно перейти $\mathrm{K}$ рассказу о замечательном событии - Всероссийской стратегической сессии по направлениям развития фотоники как "сквозной" технологии НТИ.
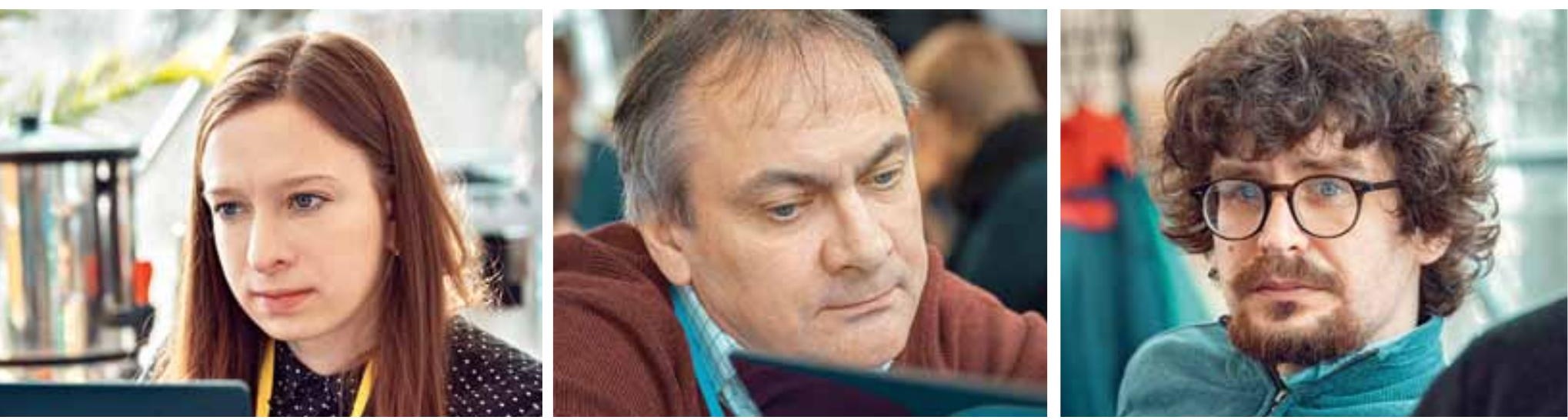

Photonics VOL. 14 № 12020 

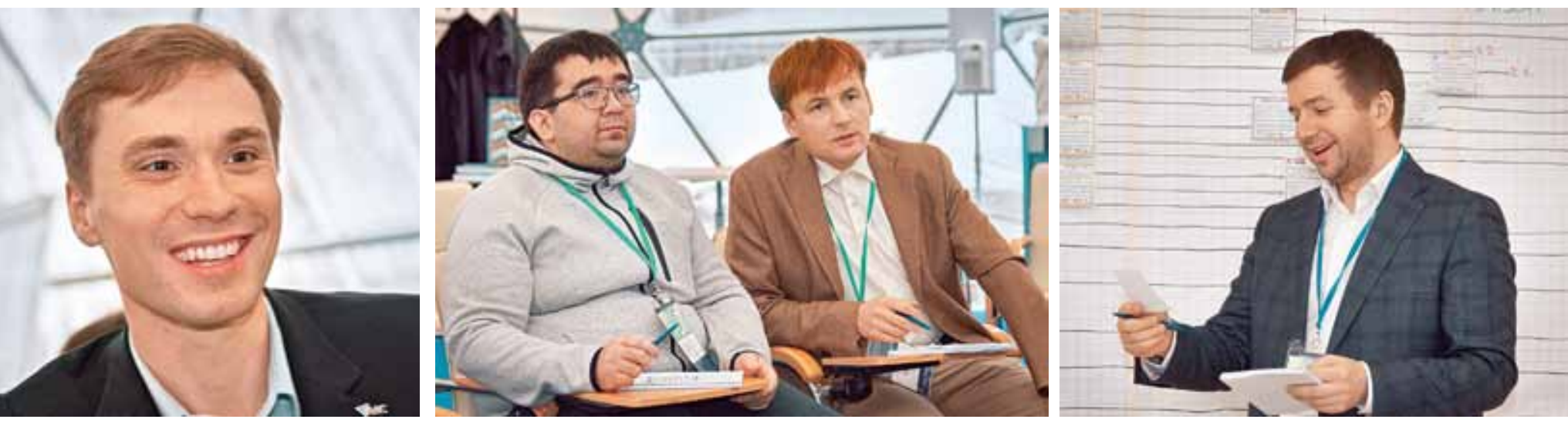

Сессия была организована правительством Пермского края, АНО "Платформа НТИ", АО "Российская венчурная компания" (Проектный офис НТИ) и кластером "Фотоника" во главе с Пермской научнопроизводственной приборостроительной компанией 20-22 февраля 2020 года в Перми. Что выделяет кластер "Фотоника" на фоне других центров компетенций, работающих с фотонными технологиями, так это развитие самых разных проектов в рамках фотоники как "сквозной" тех-

\section{Выявление противоречий и было задачей сессии}

нологии. Кластер объединил компании, занятые организацией больших данных, созданием волоконно-оптических сенсоров, Интернета вещей, робототехники, квантовых технологий и биофотоники, квантовых генераторов излучения.

Парадигма открытых инноваций лежит в плоскости коммерческих рын- ков. Но трудности с коммерциализацией научных разработок и выведением продуктов на эти рынки считаются одним из основных барьеров развития фотонных технологий. Бурный рост трафика передачи информации, ощутимый эффект от использования фотовольтаики, индустриальная фотоника, связь с Интернетом вещей через "умные оптические датчики", технологии неинвазивной медицины, моделирование цифровых двойников для симуляции работы оборудования - все эти направления открывают широкий доступ фотонике как "сквозной" технологии на современные высокотехнологические рынки.

Как оказалось, первым барьером, который пришлось преодолеть участникам сессии, стала проблема толкования базовых терминов: что такое фотоника - это наука, технология или продукция, чем фотоника отличается от оптики, как определить одним словом элементы, построенные на разных физических принципах, но связанные с генерацией излучения,
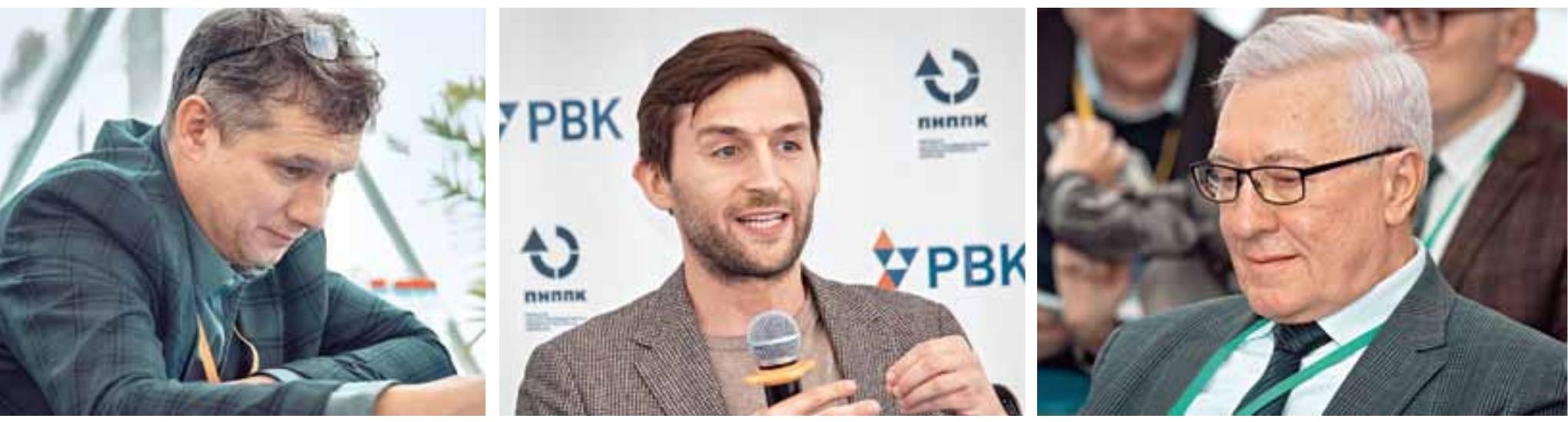

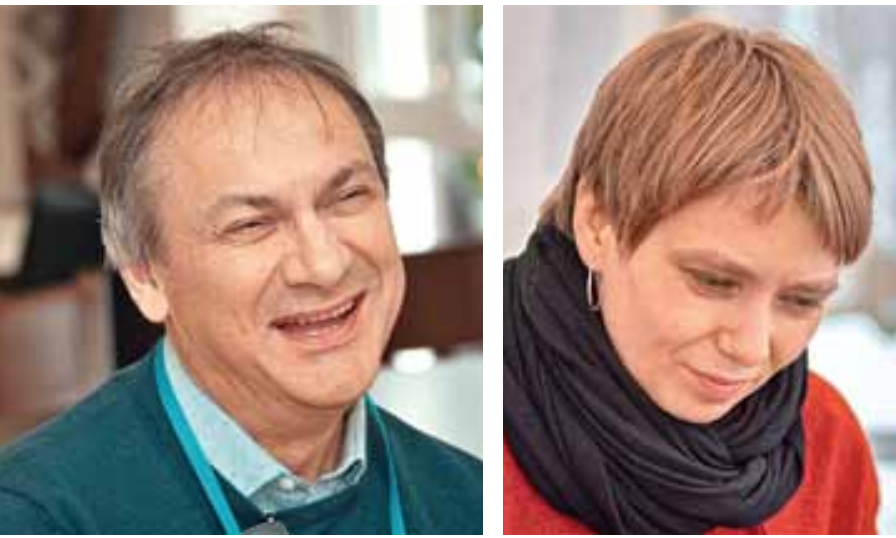

его передачей и управлением, а также обработкой сигналов. Чем сертификация отличается от метрологического обеспечения? Можно ли оценить влияние на развитие трендов инновационной политики Уральского региона, или кластер "Фотоника" охватывает разные профессиональные сообщества по всей стране?

В качестве информационной основы для разработки проектов предлагалось использовать знания фотонных, оптических и волоконно-оптических технологий участников стратегии. Затем проводились комплексные экспертные оценки. Правда, информационная база участников о трендах в этих технологиях и их подходы к прогнозированию сценариев развития трендов в сильной мере зависели от уровня компетенций и области знаний, что приводило к определенным противоречиям. Для их разрешения требуется наличие единого контентного поля. Но, по мнению организаторов, именно выявление противоречий и было задачей сессии, и задача была выполнена.

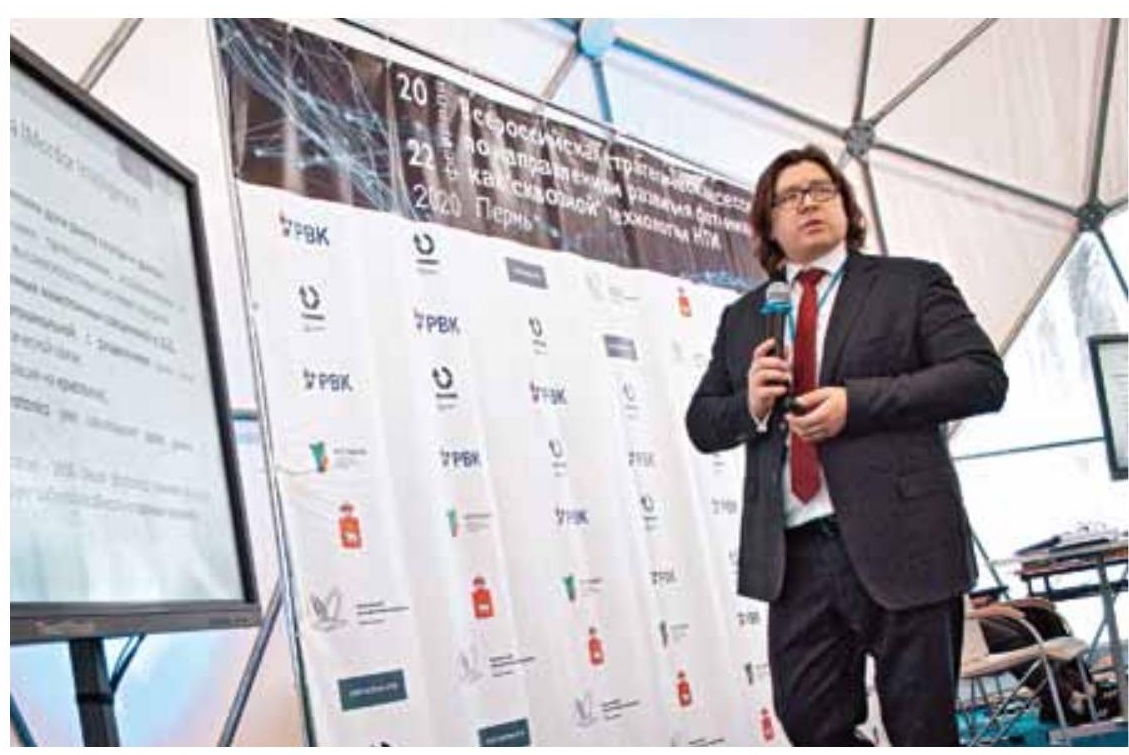

Во время работы в формате проектной сессии группы экспертов представляли собой минисетевые сообщества. Любое сетевое взаимодействие строится на коммуникации людей. Группы рассматривали полный цикл передачи технологии от разработки до готового продукта. Модераторы умело вовлекали участников сессии в совместную проектную деятельность. Базовые компетенции в области

\section{Как ни футуристически звучит идея синергии живого и искусственного, мы опасаемся оказаться во виасти умных машин}

фотоники, готовность к коллаборации помогали участникам в процессе обсуждения легко меняться друг с другом своими ролями от "защитника проекта" до
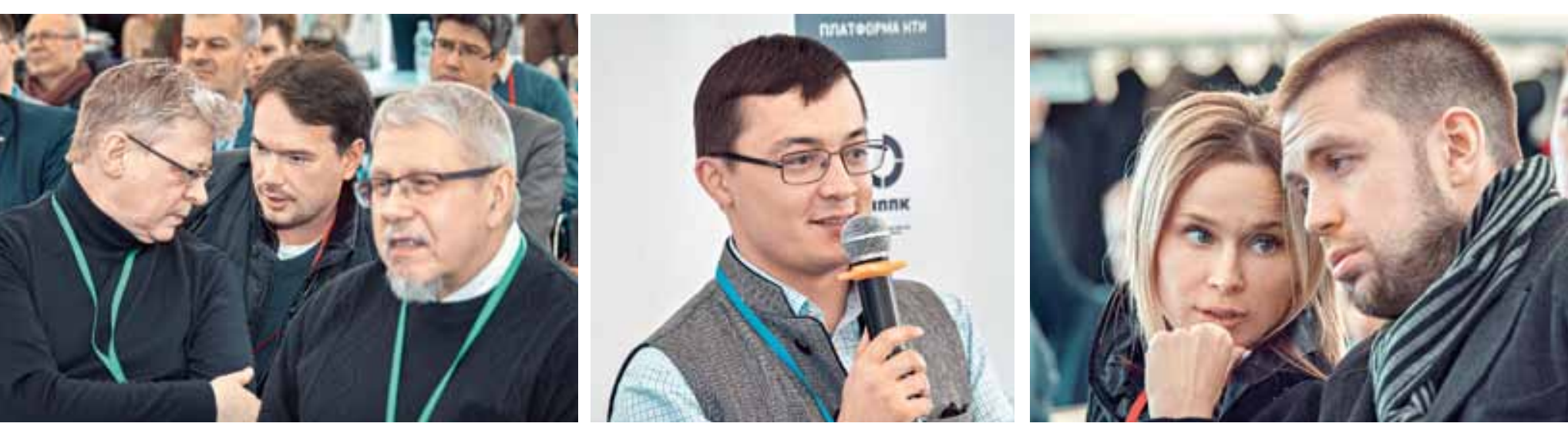

Photonics VOL. 14 № 12020 

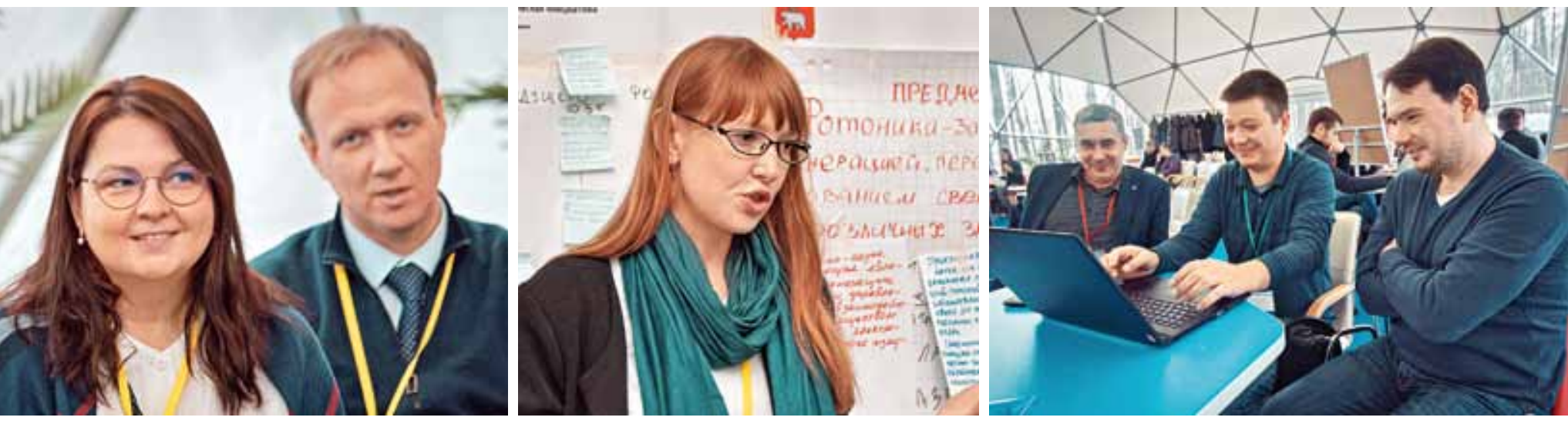

его "противника", что позволяло каждому взглянуть на свои убеждения и с критической точки зрения.

Первый день стратегической сессии был отдан проектированию минисетевых сообществ. Второй день - моделированию проектной деятельности. Завершала мероприятие защита проектов. Выбор сообщества остановился на проектах дистанционного оказания услуг, сбора информации о параметрах сложных

\section{Доля фотонных мехнологий}

\section{в высокотехнологичном секторе} экономики превысит 50\% к 2035 году

технических объектов и простых предметов быта, медицинской диагностике и анализе больших данных для принятия управленческих решений в области безопасности, спецслужбы, беспилотного транспорта, проектах обучения и создания атомно-квантовых чипов для устройств нового поколения.
Благодаря искусству модераторов разобщенные специалисты за сутки превратились в гармоничные команды профессионалов, представляя собой модель сетевого взаимодействия в горизонтальной плоскости. Поскольку успех инноваций во многом зависит от краткой качественной презентации бизнесидеи инвестору, то шла отработка презентации проектов с разных точек зрения: как развитие возможностей трендов фотоники и как, напротив, угрозы им. Процесс проектирования был построен по-разному, все зависело от компетенций участников и их ролей, которыми участники группы постоянно менялись. Формат экспертного сообщества позволил большинству участников примерить на себя роль заказчика конкурсного отбора, а наиболее смелым из них досталась роль предпринимателей.

Проект "Концерн ФотонТех" касался открытых инноваций в области фотонных технологий. В нем легко угадывались контуры организации внутреннего
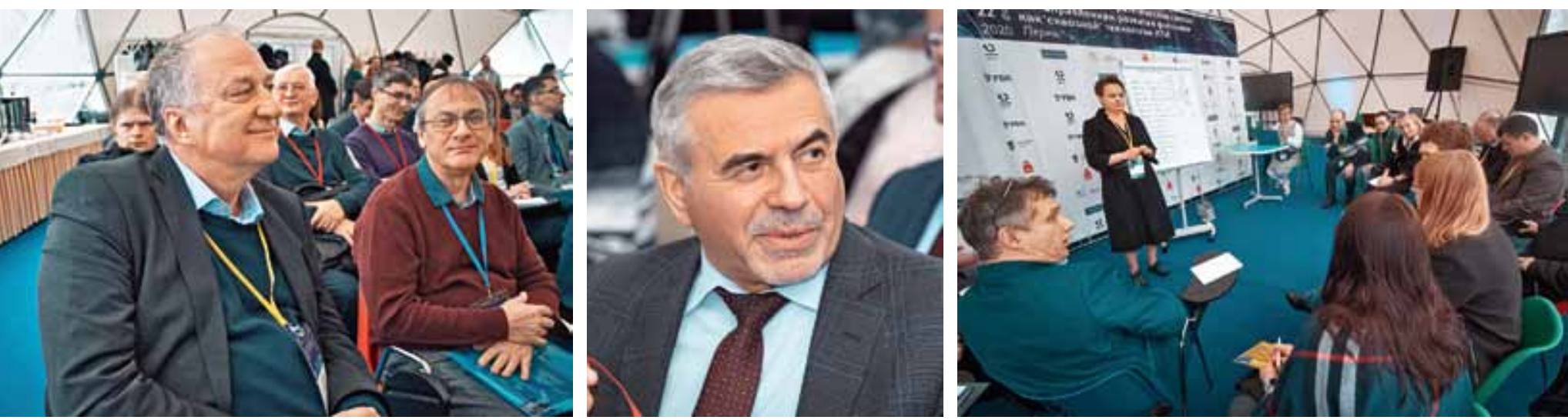

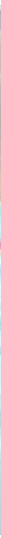

рынка через создание связей для ликвидации существующего разрыва между научными исследователями, разработчиками и производителями фотоники через устранение барьеров и просвещение потребителя.

Цель проекта "Фотонные интегральные схемы" была сфокусирована на получении быстрого эффекта накопления компетенций (научных и производственных) в радиофотонике, появлении опытных образцов ФИС и получении как системного эффекта новой российской элементной базы на основе ФИС.

«Фонд внедрения фотонных технологий (ФВФТ)» - проект, направленный на рост информационного фона о технологиях фотоники. Цель благородная, так как ментальный разрыв, существующий между исследователями и разработчиками, с одной стороны, и потенциальными потребителями фотонных изделий, с другой стороны, огромен. По сути это биржа, на которой игроки, не подозревающие о существовании рядом с ними компаньона, находят друг друга. Побочный продукт проекта - картирование НИРов.

\section{Пермский кластер "Фотоника" становится отечественным промышиенным интегратором}

Для создания банка данных о состоянии здоровья зданий и строительных сооружений было предложено снабжать каждый объект системой сенсоров и вести постоянный мониторинг за его состоянием, а затем масштабировать такую практику и сделать ее стандартной. Идея легла в основу проекта "Платформа мониторинга здоровья антропогенной среды".

Национальный проект "Умная Фотоника" в качестве эпиграфа провозгласил: "За все хорошее, против всего плохого". Его авторы прогнозируют, что доля фотонных технологий в высокотехнологичном секторе экономики превы ${ }^{-}$
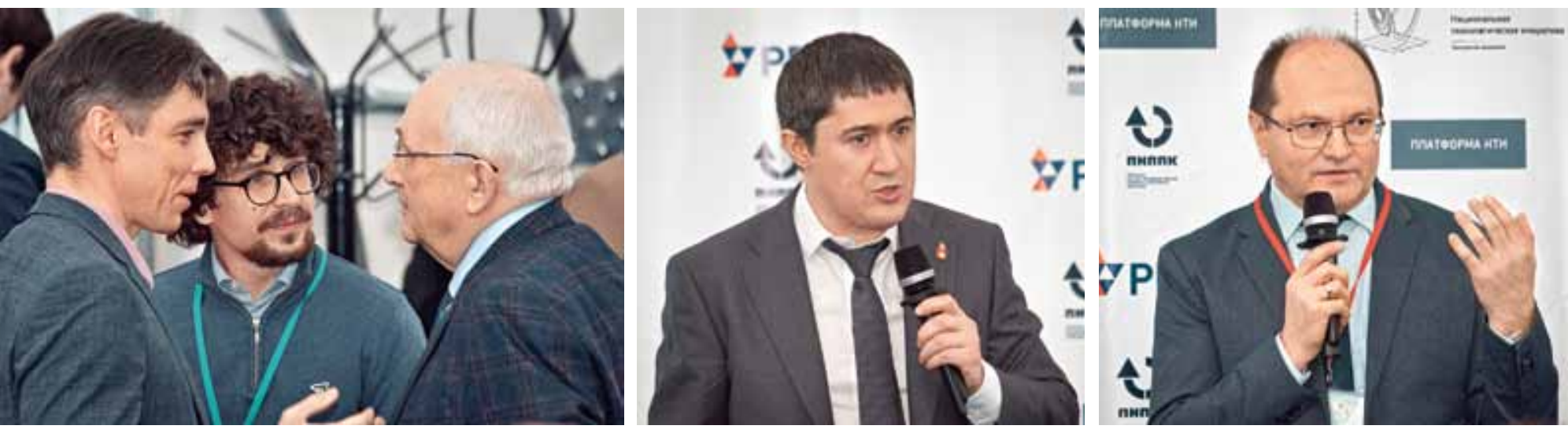

Photonics VOL. 14 № 12020 
сит 50\% к 2035 году. Суть проекта заключается в появлении нового поколения устройств фотоники: сенсоров, включая квантовые (атомные магнитометры, гравиметры, акселерометры, часы, гравиметры), фотонных приборов с искус ственным интеллектом. Цель проектной

\section{Om Homo Ludens k Homo Photonics, оставаясь при этом Homo Sapiens}

\begin{abstract}
идеи - в создании нового задела для промышленности и науки. При этом новые устройства будут иметь улучшенные ключевые показатели (чувствительность, точность, скорость обработки) на порядок величины. Результаты выполнения проекта будут определяться не численными индикаторами, а тем, что эти устройства фотоники станут для нас привычными предметами, и их можно будет просто ощутить органами чувств.
\end{abstract}

Идею зафиксировать ощущения, испытываемые вещами от действий человека, выразил проект "Интеллект вещей". Автор идеи снабдить вещи, окружающие нас в быту, датчиками, уверен, что у его проекта есть только ментальные барьеры. Они выражаются в нашей медлительности и разрозненности, в виде ограничений возможностей науки, но самое главное - в состоянии современной этики и морали. Ведь не каждый современный человек захочет сделать достоянием гласности данные от сиденья стула, на котором он провел некоторое время. Но, как ни футуристически звучит идея синергии живого и искусственного, мы опасаемся оказаться во власти умных машин.

"Диагностика и терапия при помощи лазера" - проект, посвященный использованию квантово-оптических генераторов и современных разработок в области фотоники в лечении социально проблемных заболеваний (глиома, ранняя диа-

\section{Центр компетенций по фотонике}

20 февраля в Перми начала работу Всероссийская стратегическая сессия по фотонике. В течение 3-х дней более 100 руководителей ведущих российских промышленных предприятий, вузов, научных организаций, институтов развития, представители федеральных и региональных органов исполнительной власти будут определять вектор развития фотоники и ее влияния на технологические рынки в ближайшие 15 лет.

Задачей мероприятия также является формирование концепции "дорожной карты" развития фотоники как сквозной технологии НТИ для локализации Центра компетенций НТИ по теме "фотоника" в городе Перми. Напомним, в декабре 2019 года "фотоника" была включена в перечень "сквозных" технологий Национальной технологической инициативы (НТИ). Такое решение приняла Межведомственная рабочая группа по разработке и реализации НТИ при президиуме Совета при Президенте Российской Федерации по модернизации экономики и инновационному развитию России.

На открытии стратегической сессии присутствовал врио губернатора Пермского края Дмитрий Махонин. По его словам, перед участниками собра- ния стоит серьёзная задача - наметить пути развития фотоники, и понять, какие шаги нужно сделать Пермскому краю, чтобы с её помощью выйти в лидеры в сфере высоких технологий. Наличие в регионе кластера волоконно-оптических технологий "Фотоника", организованного на базе ПАО «Пермская научно-производственная приборостроительная компания" (ПАО «ПНППК»), а также удачное расположение краевой столицы на карте России, дает все шансы стать таким Центром.

Кроме того, как отметил генеральный директор ПНППК Алексей Андреев: “Сегодня в Пермском крае создан научно-образовательный центр «Рациональное недропользование". Центр компетенций по фотонике будет являться продолжением и углублением рационального недропользования, поскольку во всех разработках по недропользованию можно использовать эту технологию. В целом же, создание Центров компетенций - это серьёзная федеральная программа с точки зрения развития фундаментальной и прикладной науки, которая предусматривает определенное финансирование именно конечных, конкретных и новых продуктов".

http://pnppk.ru/ru/press-tsentr 
гностика меланомы, тераностика, таргетированная доставка лекарств, автодинная диагностика барабанной перепонки и измерение глазного давления). Проект уже стартовал в Саратове.

Одним из главных источников роста числа перспективных проектов в рамках НТИ является стимулирование новых технологических разработок и их ускоренная коммерциализация в партнерстве с корпорациями. Именно этим целям отвечает проект "Аппарат для комплексной экспрессдиагностики здоровья человека". Он направлен на развитие всех участников рынка, проникновение готового продукта на другие высокотехнологические рынки и отвечает задачам "сквозной" технологии фотоники. Проект подразумевает разработку технологии производства лазеров на суперконтинууме среднего и дальнего ИК-диапазона $(\lambda=3-18$ мкм) для создания конкретного продукта: аппарата для экспресс-диагностики человеческого дыхания. Субъекты реализаторы: ПНППК, страховые компании, медицинские учреждения, корпоративные службы безопасности. Оздоровление населения, которое можно получить при массовом использовании этого продукта, отвечает задачам промышленной политики.

Перейти от Homo Ludens к Homo Photonics, оставаясь при этом Homo Sapiens, предлагают авторы проекта "Homo Photonics". Его авторы организуют ментальную среду таким образом, чтобы слово "фотоника" неслось из "каждого радио и каждого утюга". Проект в виде электронной открытой платформы направлен на подготовку кадров для "сквозной" технологии НТИ "Фотоника", поэтому включает в себя наряду с треком повышения квалификации разделы игротеки с играми на принципах фотоники и популярную фотонику для "чайников". Ожидаемый системный эффект от внедрения проекта отразится в популяризации фотоники и овладении фотонной грамотностью, получении компетенций в области фотоники, появлении новых коллабораций (консорциумов), проектов, производств, стартапов и т.д.

С развитием фотоники как "сквозной" технологии, пронизывающей ткань матрицы НТИ, кластер "Фотоника" притягивает к себе новые команды из Самары, Новосибирска, Красноярска, Москвы, Санкт-Петербурга, Томска, Владивостока, Ижевска. Мы с радостью наблюдаем, что пермский кластер "Фотоника" становится отечественным промышленным интегратором, которого так не хватает оптико-электронной, волоконно-оптической и квантовой индустрии.

Н. Л. Истомина, Л. В. Карякина, И. С. Шелемба

\section{$\theta$}

\section{ABECTA}

ААЗЕРЫ И ОПТИЧЕСКИЕ СИСТЕМЫ

\section{Фемтосекундные лазерные системы}

- Параметрические генераторы 340-4200 нм - Волоконные лазеры на 780, 1030-1064, 1560 нм - Лазеры со средней мощностью до 50 Вт - Оптический синтезатор частоты ("комб-генератор")

- Титан-сапфировые генераторы от 6 до 100 фс - Системы с пиковой мощностью до 15 ТВт
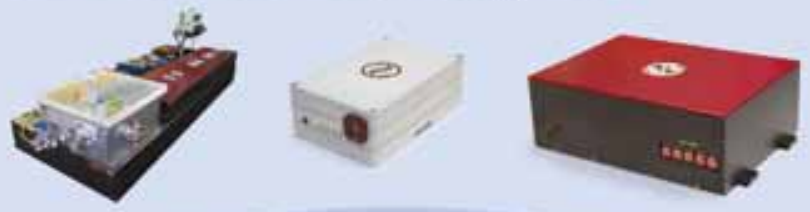

\section{Диагностика и компоненты}

- Фотоприемники с усилителем, лавинные, балансные - Изоляторы Фарадея 400-1250 нм, до 60 дБ - Селекторы импульсов на 250-2700 нм до 2 МГц - Измерители длительности импульсов, SPIDER - Электроника ФАПЧ для синхронизации

- ТТц-генераторы до 1 мДж в импульсе

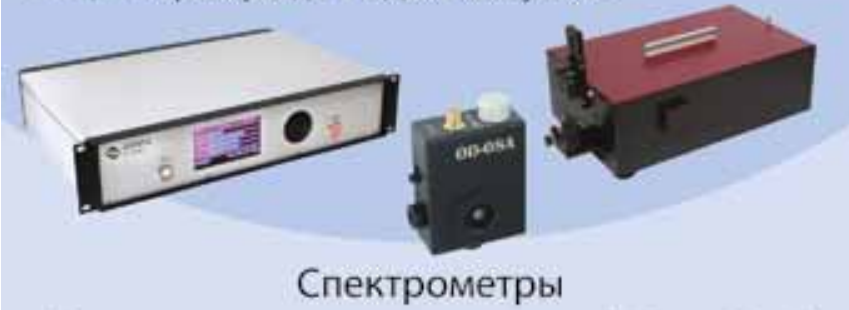

- Компактные универсальные модели (190-1100 нм) - ИК сканирующие спектрометры (500-3450 нм) - Подключение по USB, собственное ПО
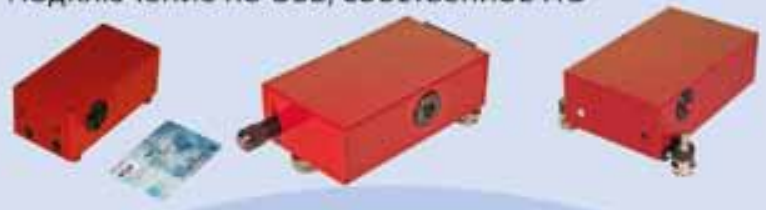

\section{Oптомеханика}

- Полный набор готовых элементов для создания оптических стендов любой сложности
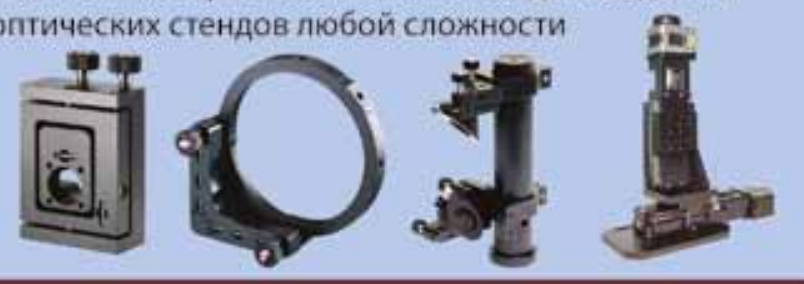

www.avesta.ru

fs@avesta.ru тел.: (495) 967-94-73; ООО "Авеста-Проект", ул. Физическая, д. 11, г. Троицк, г. Москва. 